University of Texas Rio Grande Valley

ScholarWorks @ UTRGV

$11-24-2011$

\title{
A Comprehensive Method for Fractionating Soil Organic Matter Not Protected and Protected from Decomposition by Physical and Chemical Mechanisms
}

\author{
César Plaza \\ José M. Fernández \\ Engil Isadora Pujol pereira \\ The University of Texas Rio Grande Valley, engil.pereira@utrgv.edu \\ Alfredo Polo
}

Follow this and additional works at: https://scholarworks.utrgv.edu/eems_fac

Part of the Earth Sciences Commons, Environmental Sciences Commons, and the Marine Biology Commons

\section{Recommended Citation}

Plaza, C., Fernández, J.M., Pereira, E.I.P. and Polo, A. (2012), A Comprehensive Method for Fractionating Soil Organic Matter Not Protected and Protected from Decomposition by Physical and Chemical Mechanisms. Clean Soil Air Water, 40: 134-139. https://doi.org/10.1002/clen.201100338

This Article is brought to you for free and open access by the College of Sciences at ScholarWorks @ UTRGV. It has been accepted for inclusion in School of Earth, Environmental, and Marine Sciences Faculty Publications and Presentations by an authorized administrator of ScholarWorks @ UTRGV. For more information, please contact justin.white@utrgv.edu,william.flores01@utrgv.edu. 


\section{A comprehensive method for fractionating soil organic matter into pools not protected and protected from decomposition by physical and chemical mechanisms}

César Plaza ${ }^{1}$, José M. Fernández ${ }^{2}$, Engil I. P. Pereira ${ }^{3}$, Alfredo Polo ${ }^{1}$

${ }^{1}$ Instituto de Ciencias Agrarias, Consejo Superior de Investigaciones Científicas, Serrano 115 dpdo., 28006 Madrid, Spain

${ }^{2}$ Department of Earth and Environmental Science, University of Pennsylvania, Hayden Hall, 240 S. 33rd Street, Philadelphia, PA 19104, USA

${ }^{3}$ Department of Plant Sciences, University of California, Plant and Environmental Sciences Building, One Shields Avenue, Davis, CA 95616, USA

Running title: Fractionation of soil organic matter

Correspondence: C. Plaza, Instituto de Ciencias Agrarias, Consejo Superior de Investigaciones Científicas, Serrano 115 dpdo., 28006 Madrid, Spain. E-mail: c.plaza@ica.csic.es

Abbreviations: CPMAS, cross-polarization magic-angle spinning; NMR, nuclear magnetic resonance; SOM, soil organic matter.

Keywords: Aggregates; C stabilization; Nuclear magnetic resonance; Physical fractionation; Soil organic matter 


\section{Abstract}

2 The objective of this work was to describe a method for isolating meaningful and 3 measurable soil organic matter (SOM) pools that differ in the mechanisms by which

4 they are protected from decomposition. The method is appropriate for soil C

5 stabilization and sequestration studies and is different from previous ones in that it 6 allows free SOM located between aggregates (unprotected C pool) and SOM occluded

7 within both macroaggregates and microaggregates ( $\mathrm{C}$ weakly and strongly protected by 8 physical mechanisms, respectively) to be recovered separately, freed from the soil

9 mineral matrix and the mineral-associated SOM pool ( $\mathrm{C}$ pool protected by chemical

10 mechanisms) and thus well suited to advanced chemical characterization by ${ }^{13} \mathrm{C}$ nuclear 11 magnetic resonance. Briefly, free SOM is isolated by an initial density separation. 12 Stable macroaggregates are broken up into stable microaggregates and intra13 macroaggregate SOM, which is then separated by density. Finally, intra-microaggregate 14 SOM is isolated from mineral-associated SOM by a third density separation after 15 ultrasonic disruption. The SOM dissolved during the fractionation procedure is also 16 recovered. Results obtained on soil samples with contrasting textures suggested that 17 clay content induces a decrease of the proportion of free organic $\mathrm{C}$ and an increase of 18 mineral-associated organic C content. Free SOM is characterized by a marked presence 19 of undecayed organic materials and biologically labile substances, such as 20 carbohydrates and proteins. In contrast, SOM occluded within aggregates, especially 21 within microaggregates, represents a more decomposed fraction, relatively enriched in 22 unsubstituted-aliphatic materials, most probably lipid biopolymers. 


\section{Introduction}

Soil organic matter (SOM) comprises a wide variety of plant- and animal-derived components differently susceptible to degradation, having cycling rates from weeks to millennia [1]. According to widely accepted concepts, mechanisms of SOM stabilization and protection from decomposition include: (a) occlusion within soil aggregates (physical protection), which is due to the spatial inaccessibility for decomposers, limited microbial turnover due to soil microbiota protection from predation, reduced diffusion of enzymes, and limited $\mathrm{O}_{2}$ diffusion; (b) intimate interaction with mineral particles (chemical protection), which leads to a reduced capacity of microorganisms to decompose bound substrates and to conformational changes of organic molecules which make them unavailable for soil enzymes; and (c) selective preservation and formation of SOM compounds with molecular structures more resistant to decomposition (biochemical protection) [2-4].

There is a wide body of evidence in the literature indicating that indicates that physical protection of SOM depends on the level of aggregation. In particular, C stability has shown to be much greater within microaggregates than within macroaggregates [5-7]. Based on these observations, Six et al. [3] developed a successful fractionation scheme for isolating meaningful and measurable pools of SOM that differ in cycling rates. This procedure isolates: (a) an unprotected $\mathrm{C}$ pool, which consists of free coarse particulate organic matter (i.e. $>250 \mu \mathrm{m}$ ) and represents the most labile material; (b) a physically protected C pool, consisting of the fine organic matter occluded within microaggregates; (c) a chemically-protected $\mathrm{C}$ pool, consisting of the $\mathrm{C}$ associated with the silt- and clay-sized fractions; and (d) a biochemically-protected C pool, i.e., the nonhydrolyzable organic fraction that represents the oldest and most resistant $\mathrm{C}$ pool in temperate soils. Briefly, coarse non-protected particulate organic matter, microaggregates, and silt- and clay-associated $\mathrm{C}$ are isolated by a method that 
accomplishes a complete break up of macroaggregates without breaking up

50 microaggregates, which are then separated by wet sieving. Fine unprotected particulate organic matter that is collected together with the microaggregates (i.e. $53-250 \mu \mathrm{m}$ ) is isolated by density flotation. Subsequently, microaggregates are dispersed and wet sieved to isolate microaggregate protected $\mathrm{C}$ versus silt and clay associated C. Finally, the silt- and clay-associated $\mathrm{C}$ fractions are hydrolyzed to differentiate the silt and clay protected $\mathrm{C}$ versus biochemically protected $\mathrm{C}$.

Advanced molecular characterization of unprotected and physically protected SOM fractions is of intrinsic importance to analyze $\mathrm{C}$ transformation and stabilization processes in soils. Nuclear magnetic resonance (NMR) is among the most powerful analytical tools for investigating SOM structure and composition, because it can provide

60 information on the abundance of specific functional groups and structural entities [8-

61 10]. However, the presence of soil mineral components is problematic during NMR analysis $[8,11,12]$, and has limited the application of this analytical tool to the study of the microaggregate SOM pool isolated by the method described by Six et al. [3].

Some authors have proposed physical fractionation procedures that are based on an initial density separation, which yields free light organic matter, and a second density separation after ultrasonic disruption, which gives light intra-aggregate organic matter freed from the soil mineral matrix [3-15]. In broad outline, NMR results obtained by these authors indicate that the proportion of $\mathrm{O}$-alkyl $\mathrm{C}$ is lower and that of alkyl $\mathrm{C}$ higher in the occluded light fraction than in the free light fraction, suggesting that the occluded light fraction comprises more decomposed and transformed organic matter relative to the free. Despite the importance for a better understanding of the mechanisms of $\mathrm{C}$ storage in soils, however, these studies and the method described by Six et al. [3] do not distinguish SOM pools associated with different aggregate sizes.

The objective of this work was to describe a comprehensive method for isolating 
functionally different SOM fractions mainly based on Six et al. [3] and Sohi et al. [14] that allows to recover separately free SOM located between aggregates (unprotected C pool) and SOM occluded within both macroaggregates and microaggregates ( $\mathrm{C}$ pool weakly and strongly protected by physical mechanisms, respectively) freed from the soil mineral matrix and the mineral-associated SOM pool (C pool protected by chemical mechanisms) and thus well suited to advanced chemical characterization by NMR.

81

\section{Experimental}

\subsection{Soil fractionation}

The fractionation procedure, which is schematized in Fig. 1, uses a combination of density, aggregate fractionation, and sonication procedures to separate (a) free SOM between aggregates (unprotected C pool), (b) SOM occluded within macroaggregates (C pool weakly protected by physical mechanisms), (c) SOM occluded within microaggregates ( $\mathrm{C}$ pool strongly protected by physical mechanisms), and (d) SOM associated with the mineral fractions (chemically-protected C pool); the SOM dissolved during the fractionation is also collected. In a first step, $150 \mathrm{~mL}$ of sodium polytungstate at a density of $1.85 \mathrm{~g} \mathrm{~mL}^{-1}$ is added to $20.00 \mathrm{~g}$ of $2-\mathrm{mm}$-sieved, air-dried soil in a 250 $\mathrm{mL}$ polycarbonate centrifuge bottle. The bottle is rotated at 1 revolution $\mathrm{s}^{-1}$ for $30 \mathrm{~s}$ in an overhead shaker and centrifuged at $13900 \times \mathrm{g}$ for $30 \mathrm{~min}$. The floating light fraction (free particulate $\mathrm{SOM}$ ) is separated from the heavy fraction by suction and filtration through a glass fiber filter (particle retention in liquid, $1.6 \mu \mathrm{m}$; GF/A, Whatman, UK). In a second step, macroaggregates in the heavy fraction are broken up into stable

97 microaggregates by using a microaggregate isolator $[6,16]$. In this step, the content of 98 the centrifuge bottle (i.e., the heavy fraction) is gently transferred to the top of a $250-\mu \mathrm{m}$

99 sieve, immersed in deionized water, and then shaken with 50 stainless steel beads (4 $100 \mathrm{~mm}$ in diameter) at 150 strokes $\min ^{-1}$ on a reciprocating shaker under a continuous, 
101 steady deionized water flow (about $0.2 \mathrm{~mL} \mathrm{~min}^{-1}$ ). Microaggregates and other soil

102 components smaller than $250 \mu \mathrm{m}$ are immediately flushed through the device and 103 transferred to a beaker, thus preventing the fragmentation of the microaggregates freed.

104 Shaking is stopped when water below the $250-\mu \mathrm{m}$ sieve run clear and after visually

105 checking that all macroaggregates are broken. In a third step, the fraction flushed 106 through the $250-\mu \mathrm{m}$ sieve mixed with the fraction collected over the sieve is oven-dried 107 at $70{ }^{\circ} \mathrm{C}$ and then gently transferred into a $250-\mathrm{mL}$ polycarbonate centrifuge bottle 108 together with the filtrate from the first step (sodium polytungstate solution). The bottle 109 is rotated at 1 revolution $\mathrm{s}^{-1}$ for $30 \mathrm{~s}$ and centrifuged at $13900 \times \mathrm{g}$ for $30 \mathrm{~min}$. The

110 floating particles (intra-macroaggregate SOM) are separated from the heavy fraction by 111 suction and filtration through a glass fiber filter. Finally, the heavy fraction is

112 resuspended and dispersed in the sodium polytungstate solution from the third step by 113 sonicating at an energy input of $1500 \mathrm{~J} \mathrm{~g}^{-1}$. According to previous studies on a variety of 114 soils, this ultrasonic dispersion energy is enough to maximize the breakdown of all 115 aggregates [14] while not causing detachment of SOM from primary organomineral 116 complexes and redistribution between fractions [17]. The floating particles (intra117 microaggregate $\mathrm{SOM}$ ) are recovered after centrifugation using the same procedure 118 described above for free and intra-macroaggregate SOM fractions (i.e., suction and 119 filtration through a glass fiber filter).

120 In the first step, sieves larger than $2 \mathrm{~mm}$ can be used to allow coarser aggregate 121 sizes. As in the procedure described by Sohi et al. [14], the shaking and especially the 122 centrifugation in this fractionation scheme may break up weak macroaggregares. The 123 set of shaking and centrifugation conditions (especially in terms of volume, speed, and 124 time) arguably define the intra-macroaggregate SOM proportion that is released during 125 this step. For sake of simplicity, we used the terms "free SOM" and "intra126 macroaggregate SOM" in this work, even though the terms "free SOM and SOM 
127 occulded within weak macroaggregates" and "SOM occluded within strong

128 macroaggregates", respectively, would be more accurate.

129 The residual heavy organomineral fraction recovered in the last step (mineral130 associated SOM) can be separated into sand-, silt-, and clay-size fractions as in Sohi et

131 al. [14]. Further, organomineral fractions can be hydrolyzed as in Six et al. [3] to

132 differentiate mineral protected $\mathrm{C}$ versus biochemically protected $\mathrm{C}$. It is noteworthy

133 that, unlike in Six et al. [3], the method reported here allows recovering the dissolved C

134 remaining in the fractionation medium and, also importantly, avoids the manual wet

135 sieving procedure to separate the mineral-associated $\mathrm{C}$ from the microaggregate $\mathrm{C}$ pool,

136 which is strongly dependent upon the operator's ability.

$137 \quad 2.2$ Soils

138 The protocol was tested using four replicates of two agricultural top soil samples (0-

$13920 \mathrm{~cm}$ ) with contrasting texture (Table 1). The fractions obtained were oven-dried at 70

$140{ }^{\circ} \mathrm{C}$, weighed, and ground with a mortar. Free and intra-aggregate fractions were ground

141 with the glass fiber filters to recover fine embedded particles [14]. For the NMR

142 analysis, composite samples were prepared by mixing equal weights of the four

143 corresponding replicates of each soil and soil fraction. Composite samples of the SOM

144 dissolved during the fractionation procedure (i.e., SOM remaining in the sodium

145 polytungstate solution) were also prepared by mixing equal volumes of the four

146 replicates.

$147 \quad 2.3$ Analytical methods

148 Total $\mathrm{C}$ and $\mathrm{N}$ contents of soils and SOM fractions were determined using an

149 Elementar Analysensysteme (Hanau, Germany) Vario MACRO CHNS elemental

150 analyzer, inorganic C content was determined with a Shimadzu (Duisburg, Germany)

151 TOC-5000A analyzer equipped with a SSM-5000 solid sample module, and total

152 organic $\mathrm{C}$ content was computed as the difference between total $\mathrm{C}$ and inorganic $\mathrm{C}$. 
153 Total $\mathrm{C}$, inorganic $\mathrm{C}$, and total organic $\mathrm{C}$ remaining in the composite samples of sodium

154 polytungstate solutions after fractionation (i.e., dissolved SOM pool) were determined 155 in triplicate using a Shimadzu TOC 5000A analyzer.

156 The solid-state cross-polarization magic-angle spinning (CPMAS) ${ }^{13} \mathrm{C}$ NMR spectra

157 of soils and soil fractions were obtained on a Bruker (Billerica, MA) Avance $400 \mathrm{MHz}$

158 NMR spectrometer, operating at a frequency of $100.62 \mathrm{MHz}$. Approximately $200 \mathrm{mg}$ of 159 sample was packed into a zirconium rotor of 4-mm outer diameter with a Kel-F cap.

160 The rotor spin rate was set at $5 \mathrm{kHz}$. Forty thousand scans were accumulated for each 161 sample with a pulse delay of $0.5 \mathrm{~s}$ and a contact time of $3 \mathrm{~ms}$. The NMR free induction 162 decay signals were digitized and Fourier transformed after application of a line 163 broadening of $80 \mathrm{~Hz}$. The CPMAS ${ }^{13} \mathrm{C}$-NMR spectra were then baseline corrected and 164 integrated into the following chemical shift regions: 0-45 ppm, aliphatic C; 45-110 ppm, 165 substituted-aliphatic C, including alcohols, amines, carbohydrates, ethers, methoxyl, 166 and acetal C; 110-160 ppm, aromatic C; and 160-220 ppm, carboxyl and carbonyl C.

167 The ${ }^{13} \mathrm{C}$ chemical shifts are reported relative to adamantane.

$169 \quad 3$ Results and discussion

$170 \quad 3.1$ Recoveries, $\mathrm{C}$ and $\mathrm{N}$ contents, and $\mathrm{C} / \mathrm{N}$ ratio

171 Total organic $\mathrm{C}$ recovery in free, aggregate, and mineral-associated pools after 172 fractionation is $94.5 \%$ for soil $\mathrm{A}$ and $91.6 \%$ for soil B (Table 2). The recovery rate 173 increases to $102.3 \%$ and $101.8 \%$, respectively, when the organic $\mathrm{C}$ dissolved during the 174 fractionation procedure is taken into account (Table 2).

175 Of the total organic $\mathrm{C}$ pool, free organic $\mathrm{C}$ accounts for $28.8 \%$ in soil $\mathrm{A}$ and $37.6 \%$ in soil $\mathrm{B}$, intra-macroaggragate organic $\mathrm{C}$ for $1.9 \%$ and $11.2 \%$, intra-microaggregate

177 organic $\mathrm{C}$ for $7.8 \%$ and $10.8 \%$, and mineral-associated organic $\mathrm{C}$ for $56.0 \%$ and $31.9 \%$ 178 (Table 2). The lower proportion of free organic $\mathrm{C}$ and the higher mineral-associated, or 
179 chemical protected, organic C content in soil A than in soil B indicate a larger capacity

180 for stabilization of organic materials, which may be directly related to the higher clay

181 content. Chemical stabilization capacity is believed to be mainly governed by soil clay

182 content because of the increase of specific surface area of mineral particles with

183 decreasing particle size $[19,20]$. Some data previously reported in the literature also

184 show increases in physically protected organic C with increasing soil clay content [15],

185 presumably due to the role of clays in aggregation and aggregate stability and the

186 related indirect effect on enhancing $C$ storage by occluding organic materials [20]. In

187 the current study, however, the higher proportion of intra-aggregate, or physically

188 protected, organic $\mathrm{C}$ is found in soil $\mathrm{B}$, which has lower clay but higher total organic $\mathrm{C}$

189 content. Not only clays but also organic matter is well-known to play a paramount role

190 on soil aggregation and aggregate stability [21]. Thus, the higher total organic $\mathrm{C}$ content

191 of soil B could be offsetting the lower clay content for promoting aggregate formation.

192 Regardless of the soil origin, total $\mathrm{N}$ content increases in the order intra-

193 macroaggregate $\mathrm{SOM}<$ intra-microaggregate $\mathrm{SOM}<$ free $\mathrm{SOM}<$ mineral-associated

194 SOM (Table 2). Free SOM and intra-macroaggregate SOM exhibit the largest C/N

195 ratios, whereas the smallest values are obtained for the mineral-associated SOM fraction

196 (Table 2). Factors that may be involved in lowering of the $\mathrm{C} / \mathrm{N}$ ratio include the

197 microbial transformation of plant residue material into stable organic matter and,

198 secondly, chemical fixation of $\mathrm{NH}_{3}$ or amines by lignin-like substances [21]. The results

199 obtained thus suggest that free and intra-macroaggregate SOM consists of less

200 decomposed plant residues than the organic material occluded within microaggregates,

201 which in turn represents a less decomposed fraction than the chemically protected SOM 202 pool.

203 3.2 Molecular structure of soil organic matter pools 
The CPMAS ${ }^{13} \mathrm{C}-\mathrm{NMR}$ spectra of the soil samples and of the soil fractions are

205 shown in Fig. 3, and the corresponding estimates of $\mathrm{C}$ distribution derived from the 206 NMR integration are reported in Table 3. The CPMAS ${ }^{13} \mathrm{C}-\mathrm{NMR}$ spectra of the two 207 soils and the mineral-associated SOM fractions are featureless, showing very low 208 signal-to-noise ratios (Fig. 3). These results may be related to the low C content and 209 presence of paramagnetic species containing unpaired electrons (e.g., $\mathrm{Fe}^{3+}$ ), which 210 reduce the efficiency of signal acquisition $[8,11]$. On the contrary, the CPMAS ${ }^{13} \mathrm{C}$ -

211 NMR spectra of the free and aggregate SOM fractions show well-resolved peaks, 212 having much higher signal-to-noise ratios (Fig. 3).

213 The most intense peaks in the CPMAS ${ }^{13} \mathrm{C}-\mathrm{NMR}$ spectra of the free and aggregate

214 SOM fractions of the two soils examined are in the chemical shift regions between 45 215 and $90 \mathrm{ppm}$ and between 10 to $45 \mathrm{ppm}$. The signals in the former region are primarily 216 attributed to O-substituted alkyl $\mathrm{C}$ in carbohydrates and secondarily to methoxyl $\mathrm{C}$ and $217 \mathrm{~N}$-substituted alkyl $\mathrm{C}$ in proteins, whereas the signals in the latter region are due to 218 unsubstituted-aliphatic $\mathrm{C}$ of methyl, methylene, and methine groups [8]. Other 219 important signals are also observed in the chemical shift regions due to anomeric $\mathrm{C}$ (at 220 about $105 \mathrm{ppm}$ ), unsubstituted and alkyl-substituted aromatic C (at about $125 \mathrm{ppm}$ ), aromatic $\mathrm{C}$ in phenolic groups, aromatic amines, and aromatic ethers (at about 155 ppm), carboxyl C (at about 175 ppm), and carbonyl C in ketonic groups (between 190 to $224 \mathrm{ppm})[8]$.

For both soils examined, with respect to the aggregate SOM fractions, the free SOM pool shows a smaller content of unsubstituted-aliphatic $\mathrm{C}$ and higher content of substituted-aliphatic C (Table 3). This most probably indicates greater presence of carbohydrates and proteinaceous materials arising from undecayed plant and microbial tissues. The free SOM fraction of soil A has smaller aromatic, carboxyl, and carbonyl C contents than the free SOM fraction of soil B (Table 3), probably reflecting the different 
230 plant species from which these fractions mainly derive (wheat vs. vine). Compared to

231 the macroaggregate SOM fractions, the microaggregate SOM fractions of both soils

232 feature larger aliphatic C content and smaller aromatic, carboxyl, and carbonyl C 233 contents.

234 It is noteworthy that, except for the free SOM, which mainly consists of undecayed 235 plant material, the differences in chemical structure between the SOM pools are quite 236 similar in the examined soils, which suggests that SOM decomposition and stabilization 237 follow a major similar biogeochemical pattern. Biologically labile substances arising 238 from plants and microorganisms, such as carbohydrates and proteins, are preferentially 239 and gradually lost during SOM decomposition and incorporation into macro- and 240 microaggregates, whereas unsubstituted-aliphatic materials, likely from lipid 241 biopolymers such as cutin and suberin, are preserved and accumulated in physically 242 protected fractions, especially in microaggregates.

$243 \quad 3.3$ Concluding remarks

244 The fractionation scheme described here, based on a combination of density, 245 aggregate fractionation, and sonication procedures, has proved effective to separate 246 unprotected, intra-macroaggregate, and intra-microaggregate SOM pools freed from soil 247 mineral constituents and well suited for advanced chemical characterization. Soil 248 properties, especially clay content, seem to affect the quantitative distribution of SOM 249 in the isolated SOM pools, but not their major differences in chemical composition and 250 structure, which suggests that SOM decomposition and stabilization follow a common 251 biogeochemical pattern. In particular, free organic C content is lower in the soil with 252 lower clay content, whereas mineral-associated organic C content is higher. Despite the 253 soil properties, crop, and climatic conditions, free SOM between aggregates is 254 characterized by a relatively more marked presence of undecayed organic materials and 255 biologically labile substances, such as carbohydrates and proteins. In contrast, SOM 
occluded within aggregates, especially within microaggregates, represents a more

257 decomposed fraction, relatively enriched in unsubstituted-aliphatic materials, most 258 probably lipid biopolymers. We expect that the application of this soil physical 259 fractionation procedure to SOM research will prove especially useful for characterizing

260 SOM structures and functions, as well as for developing a better understanding of the

261 mechanisms of $\mathrm{C}$ stabilization and sequestration in soils under diverse management 262 scenarios.

\section{References}

[1] D. C.Olk, E. G. Gregorich, Overview of the symposium proceedings, "Meaningful Pools in Determining Soil Carbon and Nitrogen Dynamics", Soil Sci. Soc. Am. J.

[2] P. Sollins, P. Homann, B. A. Caldwell, Stabilization and destabilization of soil organic matter: mechanisms and controls, Geoderma, 1996, 74, 65-105.

[3] J. Six, R. T. Conant, E. A. Paul, K. Paustian, Stabilization mechanisms of soil organic matter: Implications for C-saturation of soils, Plant Soil, 2002, 241, 155-

[4] M. Von Lützow, I. Kögel-Knabner, K. Ekschmitt, E. Matzner, G. Guggenberger, B. Marschner, H. Flessa, Stabilization of organic matter in temperate soils: mechanisms and their relevance under different soil conditions - a review, Eur. J. Soil Sci., 2006, 57, 426-445.

[5] J. D. Jastrow, T. W. Boutton, R. M. Miller, Carbon dynamics of aggregateassociated organic matter estimated by carbon-13 natural abundance, Soil Sci. Soc. Am. J., 1996, 60, 801-807.

[6] J. Six, E. T. Elliott, K. Paustian, Soil macroaggregate turnover and microaggregate formation: A mechanism for $\mathrm{C}$ sequestration under no-tillage agriculture, Soil Biol. 
283 [7] M. M. Pulleman, J. C. Y. Marinissen, Physical protection of mineralizable C in aggregates from long-term pasture and arable soil, Geoderma, 2004, 120, 273-282.

[8] I. Kögel-Knabner, ${ }^{13} \mathrm{C}$ and ${ }^{15} \mathrm{~N}$ NMR spectroscopy as a tool in soil organic matter studies, Geoderma, 1997, 80, 243-270.

[9] I. Kögel-Knabner, Analytical approaches for characterizing soil organic matter, Org. Geochem., 2000, 31, 609-625.

[10] A. J. Simpson, D. J. McNally, M. J. Simpson, NMR spectroscopy in environmental research: From molecular interactions to global processes, Prog. Nucl. Magn. Reson. Spectros., 2011, 58, 97-175.

[11] C. Keeler, G. E. Maciel, Quantization in the solid-state ${ }^{13} \mathrm{C}$ NMR analysis of soil and organic soil fractions, Anal. Chem., 2003, 75, 2421-2432.

294 [12] S. P. Sohi, N. Mahieu, D. S. Powlson, B. Madari, R. H. Smittenberg, J. L. Gaunt, Investigating the chemical characteristics of soil organic matter fractions suitable for modeling, Soil Sci. Soc. Am. J., 2005, 69, 1248-1255.

[13] A. Golchin, J. M. Oades, J. O. Skjemstad, P. Clarke, Study of free and occluded particulate organic matter in soils by solid-state ${ }^{13} \mathrm{C}$ CP/MAS NMR spectroscopy and scanning electron microscopy, Aust. J. Soil Res., 1994, 32, 285-309.

[14] S. P. Sohi, N. Mahieu, J. R. M. Arah, D. S. Powlson, B. Madari, J.L. Gaunt, A procedure for isolating soil organic matter fractions suitable for modeling, Soil Sci. Soc. Am. J., 2001, 65, 1121-1128.

[15] A. Kölbl, I. Kögel-Knabner, Content and composition of free and occluded particulate organic matter in a differently textured Cambisol as revealed by solidstate ${ }^{13}$ C NMR spectroscopy, J. Plant Nutr. Soil Sci., 2004, 167, 45-53. 
soils by physical fractionation, Soil Sci. Soc. Am. J., 2002, 66, 1981-1987.

309 [17] M. W. I. Schmidt, C. Rumpel, I. Kögel-Knabner, Evaluation of an ultrasonic

310 dispersion procedure to isolate primary organomineral complexes from soils, Eur. J.

311 Soil Sci., 1999, 50, 87-94.

312 [18] IUSS Working Group WRB, World Reference Base for Soil Resources, World 313 Soil Resources 103, FAO, Rome, Italy, 2006.

314 [19] M. Kleber, C. Mertz, S. Zikeli, H. Knicker, R. Jahn, Changes in surface 315 reactivity and organic matter composition of clay subfractions with duration of 316 fertilizer deprivation, Eur. J. Soil Sci., 2004, 55, 381-391.

317 [20] A. F. Plante, R. T. Conant, C. E. Stewart, K. Paustian, J. Six, Impact of soil 318 texture on the distribution of soil organic matter in physical and chemical fractions, 319 Soil Sci. Soc. Am. J., 2006, 70, 287-296.

320 [21] F. J. Stevenson, Humus Chemistry: Genesis, Composition, Reactions, John 321 Whiley \& Sons, New York, NY, 1994. 


\section{LEGENDS}

Figure 1. Fractionation scheme to isolate soil organic matter (SOM) pools unprotected and protected from decomposition by physical and chemical mechanisms. Briefly, free SOM is isolated by an initial density separation; in a second step, stable macroaggregates in the heavy fraction are broken up into stable microaggregates and intra-macroaggregate SOM, which is separated by density; finally, intra-microaggregate SOM is isolated from mineral-associated SOM by a third density separation after ultrasonic disruption.

Figure 2. Microaggregate isolator used to break up stable macroaggregates into stable microaggregates [16].

Figure 3. Solid-state cross-polarization magic-angle spinning ${ }^{13} \mathrm{C}$ nuclear magnetic resonance spectra of soil samples (A and B) before and after fractionation into free, intra-macroaggregate, intra-microaggregate, and mineral-associated soil organic matter (SOM) pools. $\mathrm{SN}$ is the signal-to-noise ratio. 


\section{Acknowledgments}

This work was supported by the Directorate-General for Universities and Research of the Community of Madrid (DGUI-CAM) and the Spanish Research Council (CSIC) through the program "Grants for Creation and Consolidation of CSIC Research Groups in the CAM" (CCG08-CSIC/AMB-3439) and by the Spanish Ministry of Science and Innovation through the VI National R\&D\&I Plan 2008-2011 (AGL2009-09124). We are grateful to Dr. David Fernández-Calviño (Department of Plant Biology and Soil Science, University of Vigo) for providing soil sample B and to Dr. C. García (Institute of Polymer Science and Technology, CSIC) for the NMR analysis. C. Plaza is grateful to the CSIC for having supplied the funds (CSIC Intramural Special Project) that made possible his visit to the University of California at Davis. The authors are also grateful to Dr. Johan Six and Dr. Pauline P. Chivenge (University of California, Davis) for their comments and constructive discussion during the preparation of this manuscript.

The authors have declared no conflict of interest. 
Table 1. Designation, origin, crop, and major properties of the soil samples used in this work.

\begin{tabular}{|c|c|c|}
\hline & Soil A & Soil B \\
\hline Sampling site & $\begin{array}{l}\text { Arganda del Rey, Madrid, } \\
\text { Spain }\end{array}$ & Verín, Galicia, Spain \\
\hline Crop & Wheat & Vine \\
\hline WRB soil group ${ }^{a}$ & Regosol & Regosol \\
\hline Texture & Clay & Sandy loam \\
\hline Sand $\left(\mathrm{g} \mathrm{kg}^{-1}\right)$ & 423 & 530 \\
\hline Silt $\left(\mathrm{g} \mathrm{kg}^{-1}\right)$ & 193 & 296 \\
\hline Clay $\left(\mathrm{g} \mathrm{kg}^{-1}\right)$ & 385 & 173 \\
\hline $\begin{array}{l}\mathrm{pH}(1: 2 \text { soil-to-water } \\
\text { ratio) }\end{array}$ & 8.5 & 5.0 \\
\hline Total organic $\mathrm{C}\left(\mathrm{g} \mathrm{kg}^{-1}\right)$ & 12.20 & 15.37 \\
\hline Total N $\left(\mathrm{g} \mathrm{kg}^{-1}\right)$ & 1.25 & 1.22 \\
\hline
\end{tabular}


Table 2. Free, intra-macroaggregate, intra-microaggregate, and mineral-associated organic $\mathrm{C}$ and total $\mathrm{N}$ contents of soil samples (A and $\mathrm{B})$ and the corresponding $\mathrm{C} / \mathrm{N}$ ratios ( \pm standard error, $\mathrm{n}=4$ ). Total organic $\mathrm{C}$ recovery in free, aggregate, and mineral-associated pools is $94.5 \%$ for soil $\mathrm{A}$ and 91.6\% for soil B (102.3\% and $101.8 \%$ when the organic C dissolved during the fractionation procedure recovered in the sodium polytungstate solution is taken into account).

\begin{tabular}{|c|c|c|c|c|c|c|}
\hline \multirow{3}{*}{$\begin{array}{l}\text { Soil organic matter (SOM) } \\
\text { pool }\end{array}$} & \multirow{2}{*}{\multicolumn{2}{|c|}{$\begin{array}{l}\text { Total organic } \mathrm{C} \\
\qquad\left(\mathrm{g} \mathrm{kg}^{-1}\right)\end{array}$}} & \multirow{2}{*}{\multicolumn{2}{|c|}{$\begin{array}{l}\text { Total N } \\
\left(\mathrm{g} \mathrm{kg}^{-1}\right)\end{array}$}} & \multirow{2}{*}{\multicolumn{2}{|c|}{$\mathrm{C} / \mathrm{N}$ ratio }} \\
\hline & & & & & & \\
\hline & Soil A & Soil B & Soil A & Soil B & Soil A & Soil B \\
\hline Free SOM & $3.51 \pm 0.21$ & $5.78 \pm 0.26$ & $0.27 \pm 0.01$ & $0.34 \pm 0.02$ & $13.0 \pm 0.2$ & $17.0 \pm 0.3$ \\
\hline Intra-macroaggregate SOM & $0.24 \pm 0.02$ & $1.73 \pm 0.03$ & $0.02 \pm 0.00$ & $0.10 \pm 0.00$ & $15.6 \pm 0.8$ & $17.5 \pm 0.2$ \\
\hline Intra-microaggregate SOM & $0.96 \pm 0.03$ & $1.66 \pm 0.10$ & $0.08 \pm 0.00$ & $0.11 \pm 0.01$ & $12.6 \pm 0.1$ & $15.9 \pm 0.8$ \\
\hline Mineral associated SOM & $6.83 \pm 0.21$ & $4.90 \pm 0.29$ & $1.15 \pm 0.04$ & $0.79 \pm 0.04$ & $5.9 \pm 0.1$ & $6.2 \pm 0.4$ \\
\hline Dissolved SOM $^{\mathrm{a}}$ & $0.94 \pm 0.01$ & $1.57 \pm 0.01$ & - & - & - & - \\
\hline
\end{tabular}

${ }^{\text {a }}$ Soil organic matter dissolved during the fractionation procedure ( \pm standard error, $\left.n=3\right)$. 
Table 3. Distribution of $\mathrm{C}$ in the free, intra-macroaggregate, and intra-microaggregate soil organic matter (SOM) pools isolated from two different soils (A and B) as estimated from CPMAS ${ }^{13} \mathrm{C}-\mathrm{NMR}$ integration.

\begin{tabular}{|c|c|c|c|c|c|c|c|c|}
\hline \multirow{4}{*}{ SOM pool } & \multirow{2}{*}{\multicolumn{2}{|c|}{$\begin{array}{c}\text { Unsubstituted-aliphatic } \mathrm{C} \\
(0<\delta \leq 45 \mathrm{ppm})\end{array}$}} & \multirow{2}{*}{\multicolumn{2}{|c|}{$\begin{array}{l}\text { Substituted-aliphatic C } \\
\qquad(45<\delta \leq 110 \mathrm{ppm})\end{array}$}} & \multicolumn{2}{|c|}{ Aromatic $\mathrm{C}$} & \multicolumn{2}{|c|}{ Carboxyl and carbonyl C } \\
\hline & & & & & $(110<$ & $0 \mathrm{ppm})$ & $(160<$ & 0 ppm) \\
\hline & \multicolumn{2}{|c|}{$(\%)$} & \multicolumn{2}{|c|}{$(\%)$} & \multicolumn{2}{|c|}{$(\%)$} & \multicolumn{2}{|c|}{$(\%)$} \\
\hline & Soil A & Soil B & Soil A & Soil B & Soil A & Soil B & Soil A & Soil B \\
\hline Free SOM & 27.5 & 31.9 & 56.8 & 41.6 & 9.2 & 13.6 & 6.5 & 12.8 \\
\hline Intra-macroaggregate SOM & 30.3 & 34.1 & 43.1 & 41.4 & 14.9 & 13.4 & 11.7 & 11.2 \\
\hline Intra-microaggregate SOM & 34.8 & 40.8 & 42.1 & 39.7 & 12.4 & 9.0 & 10.6 & 10.5 \\
\hline
\end{tabular}




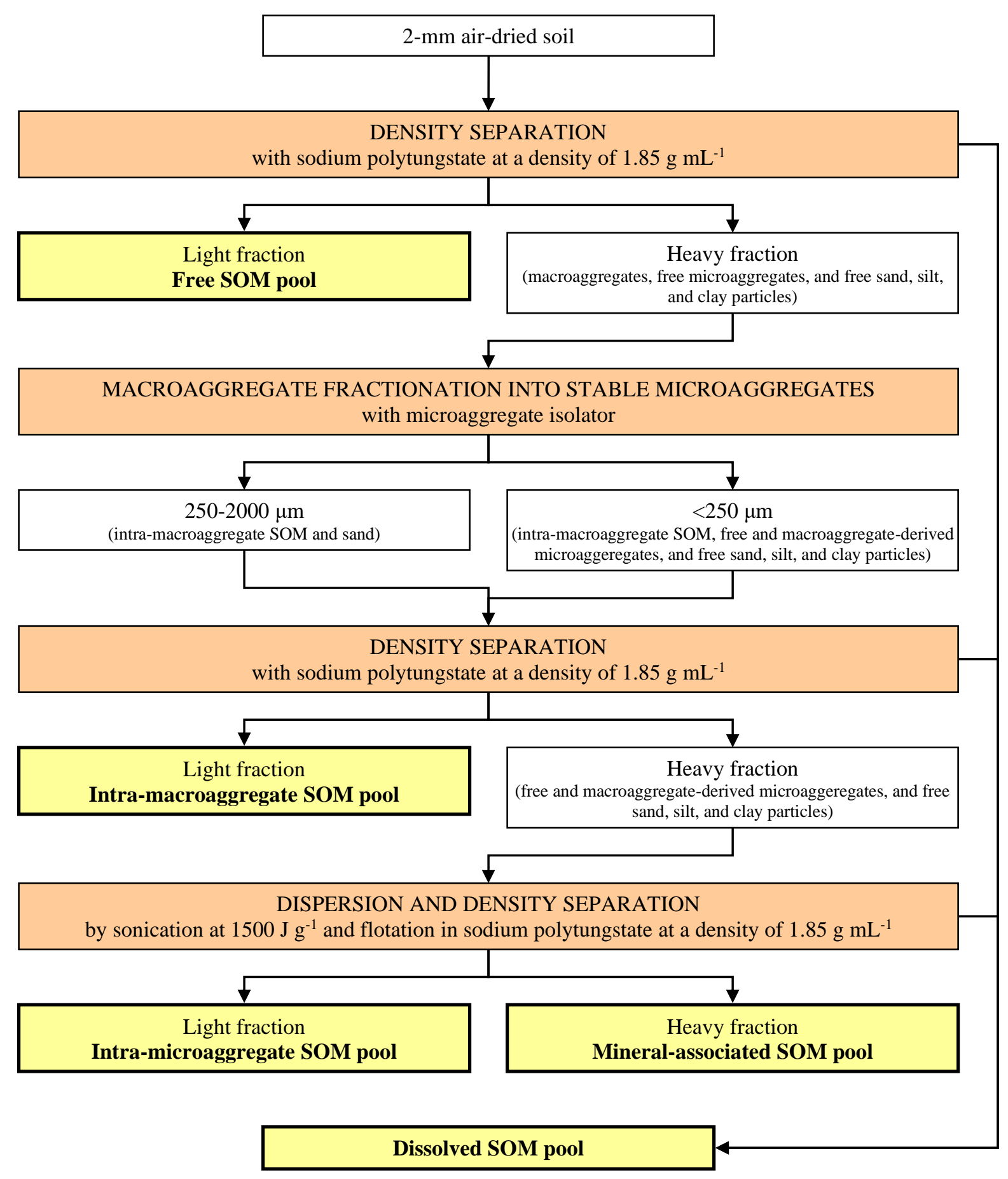



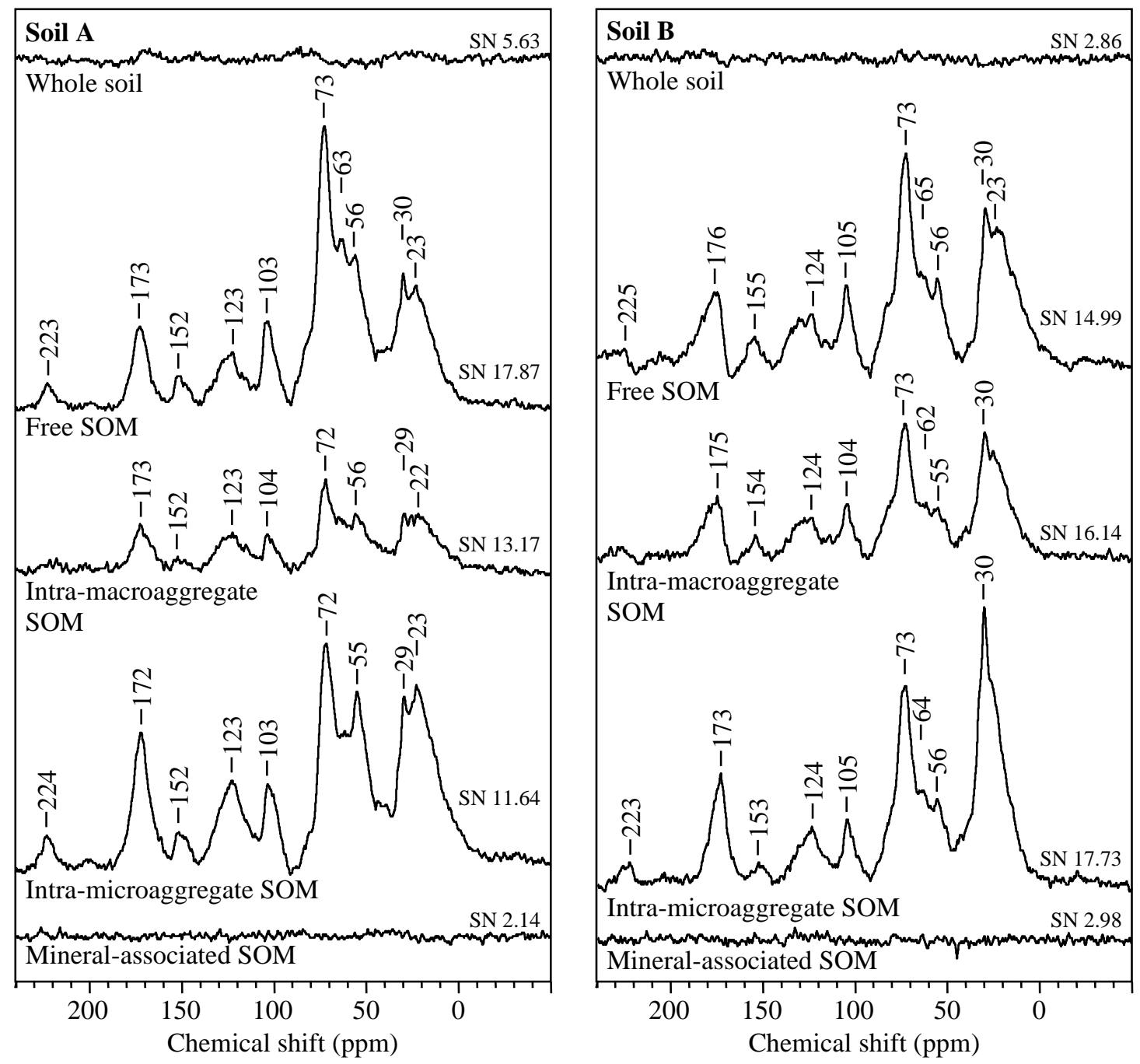